\title{
Análise de usos modais do verbo dar em entrevistas no português brasileiro
}

\author{
Cibele Naidhig de Souza \\ Universidade Estadual Paulista "Júlio de Mesquita Filho" (UNESP) \\ São José do Rio Preto, São Paulo, Brasil \\ cibelenasouza@gmail.com
}

DOI: $\underline{\text { http://dx.doi.org/10.21165/el.v45i1.804 }}$

\begin{abstract}
Resumo
Este artigo estuda padrões de comportamento linguístico do verbo dar em usos modais e busca identificar deslizamentos funcionais. A pesquisa examina entrevistas no português brasileiro do século XX retiradas do Corpus do Português, <http://corpusdoportugues.org/>. Utiliza-se, como aparato teórico-metodológico, do modelo da Gramática Discursivo-Funcional, GDF (HENGEVELD; MACKENZIE, 2008), que contempla quatro níveis gramaticais (Interpessoal, Representacional, Morfossintático e Fonológico), organizados em ordem descendente. Cada um dos níveis contempla camadas hierarquicamente estruturadas, que permitem identificar a expansão de escopos nos usos modais de dar, em direção ao nível discursivo da língua.
\end{abstract}

Palavras-chave: Gramática Discursivo-Funcional; modalidade; verbo dar.

\section{An analysis of the modal uses of the verb dar in Brazilian Portuguese interviews}

\begin{abstract}
This paper studies linguistic behavior patterns of the modal verb dar and seeks to identify functional slips. The research examines interviews in Brazilian Portuguese from the twentieth century found in the Corpus do Português [Corpus of Portuguese], http://corpusdoportugues.org/. The Functional Discourse Grammar model (HENGEVELD; MACKENZIE, 2008), which has a top-down organization of four grammatical levels (Interpersonal, Representational, Morphosyntactic and Phonological Levels), is used as a theoretical and methodological approach. Each level includes hierarchically structured layers, which allow the identification of scopes' expansion in modal uses of the verb dar toward the discursive level of the language.
\end{abstract}

Keywords: Functional Discourse Grammar; modality; dar verb.

\section{Introdução}

Embora familiares aos falantes do português, usos modais de dar ainda recebem pouca atenção dos estudiosos, razão que nos leva a oferecer, neste trabalho, uma análise desses usos $^{1}$. Interessam ao estudo ocorrências como as seguintes ${ }^{2}$ :

\footnotetext{
${ }^{1}$ Entre os poucos estudos dedicados a usos modais de dar, destacam-se Salomão (2008), Velloso (2007) e Coelho e Silva (2014), pautados em diferentes enfoques teóricos e comprometidos com objetivos também diversos.

${ }^{2}$ As ocorrências apresentadas são retiradas do Corpus do Português (http://www.corpusdoportugues.org).
} 
(1) Em festas da escola, havia sempre quem recitasse poesias desses poetas e também de outros. A mim nunca pilharam para declamar, não dou para essas exibições.

(2) a) Da jaula dos leões, daria para escutar a conversa.

d) Eu tentei fazer uns sambas, mas não deu. Samba é diferente.

(3) Não dá para ir de roupa curta na missa.

Considere-se que essas ocorrências permitem interpretações amplamente aceitas como modais (PALMER, 1986; AUWERA; PLUNGIAN, 1998; HENGEVELD, 2004; entre outros), a saber: facultativas/dinâmicas - referentes à habilidade/capacidade de um participante (ter vocação, tendência, aptidão), como em (1), ou a condições circunstanciais que "habilitam" a ocorrência do evento (ser possível), como em (2); e deônticas - referentes àquilo que é permissível com base em alguma norma (legal, moral, social etc.), como em (3).

O objetivo deste artigo é estudar usos modais do verbo dar, buscando-se identificar deslizamentos funcionais e verificar tendência à cristalização em alguns padrões.

Em uma perspectiva funcionalista, examinam-se textos de entrevistas do português brasileiro do século $\mathrm{XX}$ retirados do Corpus do Português, disponível em $<$ http $/ /$ www.corpusdoportugues.org $>$. Esse banco de dados abriga mais de 45 milhões de palavras do português (brasileiro e europeu) distribuídas por diversas sincronias (século XIV a século XX) e diferentes gêneros de fala e de escrita.

Em relação à estrutura do artigo, primeiramente delimita-se a base teórica que sustentará o exame. Nas duas seções seguintes, $A G D F$, aparato teórico-metodológico e As modalidades na GDF, apresentam-se pressupostos da Gramática DiscursivoFuncional (GDF, daqui em diante), a classificação das modalidades e o modo como desenvolvimentos gramaticais e discursivos podem ser estudados nesse modelo. As duas seções que seguem a parte teórica são dedicadas à análise dos usos modais de dar e às generalizações sincrônicas que $\mathrm{o}$ exame permite inferir. Encerram $\mathrm{o}$ texto as considerações finais.

\section{A GDF, aparato teórico-metodológico}

As propriedades dos enunciados são adaptáveis aos objetivos comunicativos que o usuário procurar atingir ao usar tais enunciados. A GDF assume esse pressuposto funcionalista e busca descrever os enunciados alinhando a expressão a condicionamentos discursivos.

A GDF é um modelo teórico da gramática, que apresenta níveis ordenados hierarquicamente, em progressão top-down (de cima para baixo), do discurso para as unidades menores. Assim, esse modelo de gramática busca refletir em sua organização o processamento linguístico dos falantes.

A arquitetura geral do modelo, como se pode observar pela figura 1, é constituída de quatro componentes (conceitual, contextual, gramatical e de saída), sendo a GDF o componente gramatical de um modelo mais amplo de interação verbal. 


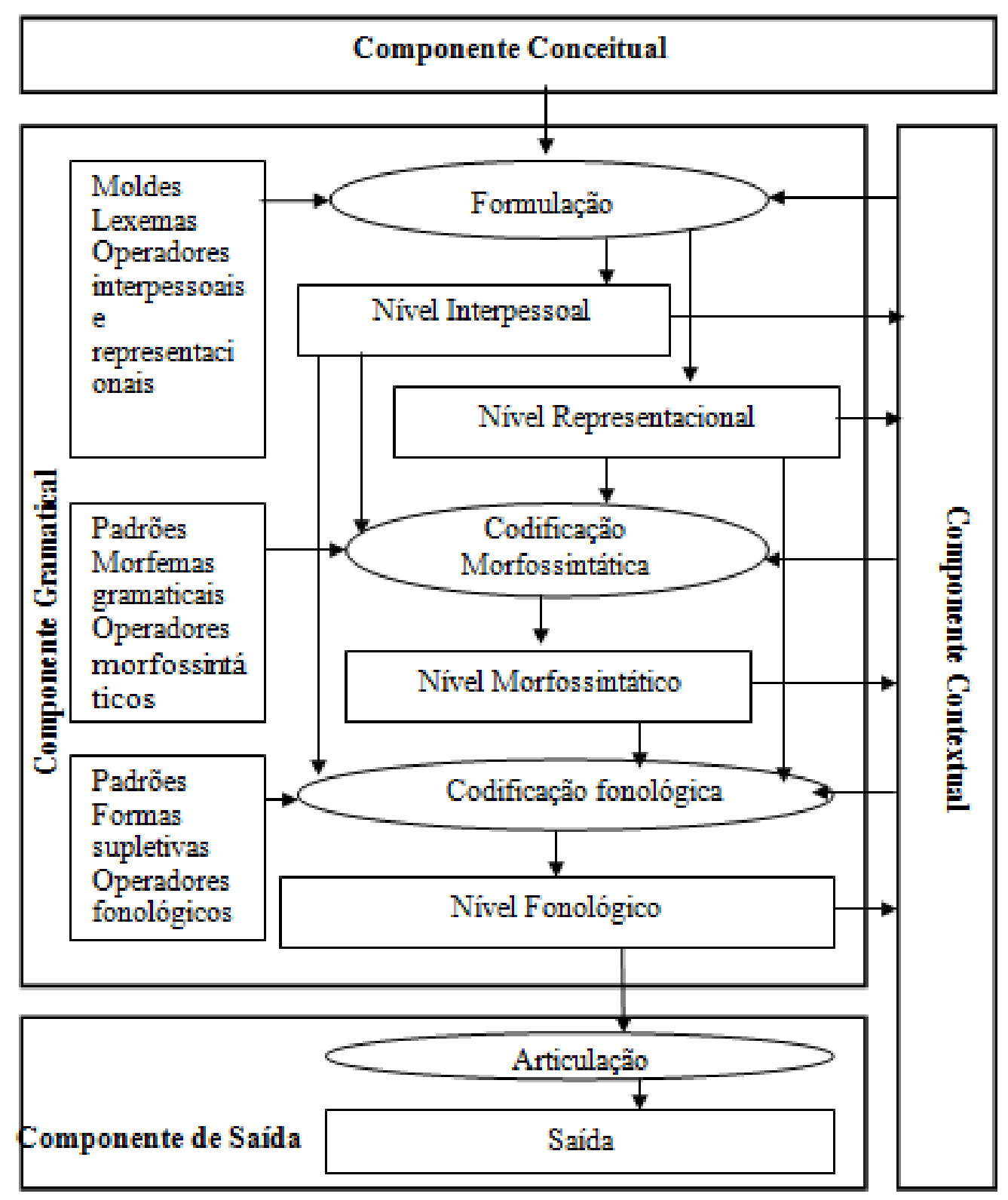

Figura 1 - Arquitetura geral da Gramática Discursivo-Funcional

Fonte: Hengeveld e Mackenzie (2008, p.13)

O Componente Gramatical é composto por níveis interligados e organizados de modo descendente: Nível Interpessoal (NI), Nível Representacional (NR), Nível Morfossintático (NM) e Nível Fonológico (NF). Nessa organização descendente, primeiramente se decide o propósito comunicativo para depois se selecionar e se codificar essa informação gramaticalmente: a pragmática governa a semântica, a pragmática e a semântica governam a morfossintaxe, e a pragmática, a semântica e a morfossintaxe governam a fonologia.

Dois processos estão envolvidos na produção linguística, a formulação e a codificação. O NI e o NR são os níveis de formulação, o NM e o NF são os níveis de codificação. Cada um dos níveis é estruturado em camadas de vários tipos, também hierarquicamente organizadas. 
No NI, captam-se as distinções de formulação que dizem respeito à interação entre falante e ouvinte, descrevem-se estratégias para se alcançar objetivos comunicativos. Em ordem hierárquica decrescente quanto ao escopo, as camadas do NI são: Movimento (M) > Ato Discursivo (A) > Ilocução $(\mathrm{F})>\operatorname{Participantes~}(\mathrm{P})>$ Conteúdo Comunicado (C) >Subato de Atribuição (T) > Subato Referencial (R).

No NR, as unidades são descritas em termos de categorias semânticas que elas designam. As camadas do NR, em ordem hierárquica decrescente quanto ao escopo, são: Conteúdo Proposicional (p) > Episódio (ep) > Estado-de-coisas (e) > Propriedade Configuracional (f) $>$ Propriedade lexical > Indivíduos (x).

As informações semânticas e pragmáticas do NI e do NR são codificadas no NM, que é responsável pelas representações estruturais que serão convertidas em construções fonológicas no nível seguinte, o NF. Como todos os níveis da GDF, o NM é estruturado em camadas ordenadas de modo decrescente: Expressão Linguística (Le) > Oração $(\mathrm{Cl})>$ Sintagma $(\mathrm{Xp})>$ Palavra $(\mathrm{Xw})>$ Base $(\mathrm{Xs})>$ Afixo (Aff).

Como o NM, o NF trata de aspectos de codificação. O Componente Fonológico recebe input dos outros níveis e o traduz em estrutura fonológica. Em organização hierárquica decrescente, as camadas do NF são: Enunciado (U) > Frase Entoacional (IP) $>$ Frase Fonológica $(\mathrm{PP})>$ Palavra fonológica $(\mathrm{PW})>$ Pé $(\mathrm{F})>$ Silaba $(\mathrm{S})$.

Oferecida essa visão panorâmica da GDF, com apresentação de aspectos mais relevantes para este estudo, considere-se, então, como o modelo permite capturar desenvolvimentos gramaticais e discursivos, interpretados como próprios de gramaticalização. Embora não seja intuito deste trabalho descrever usos modais de dar na perspectiva da gramaticalização, o que é uma interessante direção de estudos e será tema de outro escrito, examinar padrões de comportamento linguístico dos usos modais de dar à luz da GDF leva, necessariamente, a reconhecer diferentes graus de gramaticalidade.

Assume-se que alterações próprias da gramaticalização, processo de mudança linguística pelo qual uma palavra ou expressão lexical torna-se gramatical ou, se já gramatical, torna-se cada vez mais gramatical (HEINE et al., 1991; TRAUGOTT; HEINE, 1991; HOPPER; TRAUGOTT, 2003; entre outros), podem ser sistematicamente descritas de um modo produtivo utilizando o aparato teórico da GDF, como têm mostrado trabalhos como Keizer (2007), Souza (2009), Hengeveld (2011, no prelo), Olbertz (2010), Casseb-Galvão (2011), Hengeveld e Hattnher (2016).

$\mathrm{Na}$ GDF, a gramaticalização é compreendida como envolvendo mudanças formais e de conteúdo. Em relação ao conteúdo, os processos de gramaticalização acarretam gradualmente um aumento sistemático de escopo nas camadas e níveis, enquanto na questão formal acarretam um decréscimo sistemático de lexicalidade. (HENGEVELD, no prelo, p.1). Mudanças discursivas e de conteúdo são independentes, mas interagem, de modo que se um item tem seu escopo aumentado, não pode descer na escala de mudanças formais, e vice-versa. A figura seguinte ilustra percursos de alteração de escopo previstos na GDF. 


\begin{tabular}{|c|c|c|c|c|c|c|c|c|c|}
\hline \multirow[t]{2}{*}{$\begin{array}{l}\text { Nível } \\
\text { Interpessoal }\end{array}$} & $\begin{array}{l}\text { Ato } \\
\text { Discursivo }\end{array}$ & $>$ & llocução & $>$ & $\begin{array}{l}\text { Conteúdo } \\
\text { Comunicado }\end{array}$ & $>$ & $\begin{array}{l}\text { Subato de } \\
\text { Referência }\end{array}$ & $>$ & $\begin{array}{l}\text { Subato de } \\
\text { Atribuição }\end{array}$ \\
\hline & & & & & V & & & & \\
\hline $\begin{array}{l}\text { Nivel } \\
\text { Representa } \\
\text { cional }\end{array}$ & Proposição & $>$ & Episódio & $>$ & $\begin{array}{l}\text { Estado de } \\
\text { coisas }\end{array}$ & $>$ & $\begin{array}{l}\text { Propriedade } \\
\text { configuracional }\end{array}$ & $>$ & Propriedade \\
\hline
\end{tabular}

\section{Figura 2 - Relações de escopo na GDF}

Fonte: Hengeveld (no prelo, p.3)

A figura mostra que o modelo prevê três tipos de relações de escopo, com trajetórias nas camadas do NR (Proposição > Episódio > Estado-de-Coisas > Propriedade Configuracional), nas camadas do NI (Ato Discursivo > Ilocução > Conteúdo Comunicado > Subato de Referência > Subato de Atribuição), e do NR para o NI.

\section{As modalidades na GDF}

As distinções modais de Hengeveld (2004) são retomadas no modelo da GDF. A proposta surge do cruzamento de dois parâmetros, o alvo e o domínio da avaliação modal.

De acordo com o alvo ${ }^{3}$, as modalidades são subdivididas em três tipos, alocadas em diferentes camadas do NR:

a) na camada das Propriedades Configuracionais (f) ${ }^{4}$, orientada para o participante - afeta a parte relacional da sentença como expressa por um predicado e se refere à relação entre (propriedades de) um participante em um evento e a potencial realização desse evento (exemplos: João sabe jogar xadrez, A aluna pode entrar na sala (foi autorizada), etc.);

b) na camada dos Estados-de-coisas $(e)^{5}$, orientada para o evento - afeta a descrição do evento contido na sentença, ou seja, a parte descritiva de uma sentença e se refere à avaliação objetiva do estatuto de atualidade do evento; em outras palavras, descreve a existência de possibilidades, obrigações gerais, etc., sem que o falante tome responsabilidade por esses julgamentos (exemplos: Proibido fumar, $O$ arquivo não pode ser anexado, etc.);

\footnotetext{
${ }^{3}$ Em trabalho posterior, Hengeveld (2011) distingue um quarto alvo de avaliação modal, a modalidade orientada para o episódio que, em Hengeveld (2004), foi considerada como um subtipo de modalidade, a orientada para o evento epistêmica (objetiva). Hengeveld (2011) indica que a modalidade epistêmica objetiva caracteriza episódios em termos da (im)possibilidade de sua ocorrência em vista daquilo que é conhecido sobre o mundo. Na modalidade orientada para o episódio, o tempo é absoluto, independente, e, na modalidade orientada para o evento, o tempo é relativo, dependente. Essa modificação da classificação não será considerada, porque, para este estudo, não é relevante.

${ }^{4}$ A Propriedade Configuracional (f) não tem existência independente, não pode ser distinta em termos de tempo e de espaço, e somente pode ser avaliada em termos de sua aplicabilidade a um ou outro tipo de entidade ou a situação que as propriedades em geral descrevem (por exemplo, cor).

${ }^{5}$ Estados-de-Coisas (e) podem ser localizados no tempo e no espaço, e podem ser avaliados em termos de sua realidade (por exemplo, encontro).
} 
c) na camada do Conteúdo Proposicional $(\mathrm{p})^{6}$, orientada para a proposição - afeta o conteúdo proposicional de uma sentença, ou seja, a parte da sentença que representa as visões e as crenças do falante e diz respeito à especificação do grau de comprometimento do falante em relação à proposição que ele está apresentando (exemplos: Pode ser que chova no dia do casamento de Bela, Eu acho que Lígia errou ao fazer aqueles comentários, etc.).

Em relação à variação na perspectiva da avaliação modal (o domínio da avaliação), Hengeveld (2004) propõe os seguintes tipos: facultativa (referente à capacidade intrínseca ou adquirida); deôntica (referente àquilo que é permissível legalmente, socialmente, moralmente); volitiva (referente àquilo que é desejável); epistêmica (referente àquilo que se conhece sobre o mundo atual); evidencial (referente à origem da informação contida sobre o mundo atual).

As combinações possíveis entre os domínios e os alvos modais são apresentadas no quadro seguinte.

Quadro 1 - Classificação das modalidades segundo Hengeveld (2004)

\begin{tabular}{|c|c|c|c|}
\hline Domínio Alvo & Participante & Evento & Proposição \\
\hline facultativa & + & + & - \\
\hline deôntica & + & + & - \\
\hline volitiva & + & + & - \\
\hline epistêmica & - & + & + \\
\hline evidencial & - & - & + \\
\hline
\end{tabular}

A relação hierárquica das camadas nas quais se alocam as modalidades orientadas para o participante, para o evento e para a proposição permite descrever diferentes graus de gramaticalidade de elementos modais. É possível, então, supor trajetos de desenvolvimento gramatical no campo modal, como representado pela figura seguinte:

\section{Nível Representacional}

(f) >

Propriedades Configuracionais

(modalidade orientada para o

falante) (e) >

Estados-de-Coisas

(modalidade orientada para o

evento) (p)

Conteúdo proposicional (modalidade orientada para a proposição)

Figura 3 - Hipótese de gramaticalização no campo modal, segundo a GDF

Essas hipóteses de percurso são compatíveis, como destacam Hengeveld; Hattnher (2016), com previsões de encaminhamentos de gramaticalização no campo modal formulados por outros pesquisadores, pautados em outros modelos teóricos como, por exemplo, Traugott e Dasher (2002) e Bybee et al. (1994). O que esses estudos apontam é que o desenvolvimento no campo modal se dá do mais concreto ao mais abstrato, com aumento gradual de subjetividade.

Traugott e Dasher (2002, p. 147) postulam que o desenvolvimento modal se dá, sempre, na direção de significados deônticos para epistêmicos, de escopo mais restrito

${ }^{6}$ O Conteúdo Proposicional (p), sendo um construto mental, não pode ser localizado no espaço nem no tempo, e pode ser avaliado em termos de sua verdade (por exemplo, ideia). 
para escopo mais amplo (âmbito de incidência dentro da proposição para âmbito de incidência sobre proposição), de aumento de grau de subjetividade, o que é condizente com o trajeto proposto pela GDF (figura 3).

A proposta de Bybee et al. (1994, p.194) para o desenvolvimento em direção aos valores epistêmicos, habilidade > possibilidade de raiz/permissão > possibilidade epistêmica, também aponta aumento de subjetividade e de abstratização. O percurso de mudança prevê que, de um significado mais concreto, habilidade, desenvolvem-se significados mais abstratos, mais subjetivos, mais centrados nas crenças e opiniões do falante (valores epistêmicos), desenvolvendo-se, antes, a possibilidade de raiz e a permissão. Note-se que tal hipótese é compatível com a da GDF (figura 3).

\section{Análise de usos modais de dar}

No exame de entrevistas do Corpus do Português, localizaram-se 165 ocorrências de usos modais de dar. Com base na classificação das modalidades adotada (HENGEVELD, 2004), observou-se que dar concentra-se fortemente no valor facultativo orientado para o evento (97\% das ocorrências, 160/165), como em (4). Há, ainda, algumas poucas ocorrências do tipo deôntico orientado para o evento ( $1 \%$ das ocorrências, 2/165) como (5), e aquelas em que não é possível decidir com clareza entre o valor facultativo ou deôntico orientado para o evento (2\% das ocorrências, 3/165), como (6).

(4) JC - Você acredita que a relação das rádios e da mídia em geral com a música pernambucana mudou depois da morte de Chico Science? Fred - Nos grandes veículos já dá para sentir uma diferença. Os jornais do Sul e o Multishow, por exemplo, começaram a demonstrar um maior interesse pela nova cena de Pernambuco. O público também tem acompanhado isto. Até o SescPompéia, uma das maiores casas de São Paulo, está interessado em fazer um evento mensal com as bandas daqui.

(5) Uma grande editora brasileira também quis investir no personagem, mas não conseguiu classificá-lo. Não sabiam se era adulto, infantil... Pornográfico... Sei lá... Foi sempre muito difícil publicá-lo. Todos dizem que ele tem potencial mas não foi explorado "comercialmente". Eu não estou fazendo estas mudanças por que quero fazê-lo dar certo apenas comercialmente. Quero que ele dê certo pra mim. Eu mudei. Tenho filhos. Tenho quase 40 anos agora e vejo as coisas muito diferentes. Não dá pra fazer um personagem que não retrate pelo menos um pouco do que o autor é.

(6) E o JB basicamente é um jornal carioca, é um jornal carioca da Zona Sul. E aí deu uma confusão ficou só quatro meses, mas foi uma loucura. Então dali pra cá é uma decadência total, é o processo final. Porque um jornal custa a morrer, tem muito tempo até sumir por completo; mas, pra mim, o Jornal do Brasil está morto. Não traz mais nenhuma informação que seja relevante, publica matérias como se fosse uma sede da agência Brasil, que é a agência oficial do governo, ou seja, não dá pra levar assim, isso um jornalzinho do interior pode fazer. Esse tipo de matéria que parece da agência Brasil seriam matérias pagas? Eu não vou dizer que sim porque eu não presenciei isso, mas houve uma orientação no sentido de que os repórteres buscassem o faturamento, o que é o contrário do que reza a ética jornalística e os espaços de coluna social eu tenho certeza que são vendidos - você não abre a página de um jornal pra ver a festa que aconteceu no final de semana de alguém.

Em (4), dá tem o sentido de ser possível, em termos de condições favorecedoras para a ocorrência do evento descrito na sentença, que caracteriza a modalidade facultativa orientada para o evento. A ocorrência (4) pode ser parafraseada por existem 
condições circunstanciais que possibilitam sentir uma diferença, em relação ao modo como as rádios e a mídia em geral consideram a música pernambucana.

$\mathrm{Na}$ ocorrência (5), dá também permitiria uma paráfrase com ser possível, mas, nesse caso, identifica-se uma orientação de conduta, então, um sentido mais adequado seria em termos de ser permitido. A fonte deôntica, em (5), é pautada em regras de comportamento que o informante, um escritor, adota, segundo as quais não é permitido, sendo uma pessoa madura (tem filhos, 40 anos de idade), realizar determinado trabalho (elaborar um personagem que não tenha nenhuma relação com ele). Configura-se, aí, a modalidade deôntica orientada para o evento, que caracteriza estados de coisas em termos daquilo que é obrigatório ou permitido, com base em um sistema de convenções morais ou legais, regras de conduta, de modo geral, não referentes a um participante em particular (HENGEVELD; MACKENZIE, 2008, p. 174).

As leituras facultativa e deôntica seriam possíveis para a ocorrência (6). Em uma interpretação facultativa, não dá para levar assim, em (6), seria entendido como não há condições que favoreçam o jornal continuar (o jornal não traz nada que seja relevante, publica matérias como se fosse uma sede da agência Brasil, faz coisas que um jornal de interior faz). Seria possível, também, compreender que não é permitido ao jornal continuar, com base em um sistema de ética jornalística que não permite que, nas condições descritas, o jornal continue, e, então, a leitura seria deôntica.

Não foi localizado, nas ocorrências examinadas, o valor modal facultativo orientado para o participante, que descreve a habilidade, intrínseca ou adquirida, de um participante de se envolver no tipo de evento designado pelo predicado. Embora não ocorrentes no conjunto de textos selecionados para exame neste estudo, usos do verbo dar são bastante conhecidos dos falantes do português. $\mathrm{O}$ enunciado (1), localizado em uma crônica de Zélia Gattai no Corpus do Português, reapresentado como (7), é um exemplo.

(7) Em festas da escola, havia sempre quem recitasse poesias desses poetas e também de outros. A mim nunca pilharam para declamar, não dou para essas exibições.

Nesse caso, o verbo dar expressa capacidade do sujeito, interpretada em termos de vocação, jeito, aptidão, tendência para algo. Em (7), a personagem diz que não tem vocação, talento para exibições. Considere-se que (7) é uma sentença negativa, mas que esse valor modal se realiza com o verbo dar também na forma afirmativa, como é possível verificar em outros corpora. Salomão (2008, p.84), por exemplo, apresenta o seguinte enunciado: Carlos dá para linguista.

$\mathrm{Na}$ escala dos valores modais, o uso facultativo orientado para o participante, como em (7), é o mais concreto, baseado em descrições de situações externas. Nesses casos, dar é verbo pleno, organizador de predicação, e o padrão estrutural é:

Padrão I - $[\mathrm{Np}+\text { DAR PARA + Np }]^{7}$

Diferentemente dos usos facultativos orientados para o participante, nos facultativos ou deônticos orientados para o evento, como (4) e (5), o verbo dar não é um organizador de predicação, um verbo pleno. O padrão estrutural desses usos é:

Padrão II - [DAR PARA + Vp FORMA Não FinIta $_{\text {ESTRUTURA IMPESSOAL }}{ }^{8}$

\footnotetext{
${ }^{7} \mathrm{~Np}$ é nounphrase, sintagma nominal.
} 
Nesse padrão, o verbo dar assume sempre a forma impessoal, atua como um quase-auxiliar (HEINE, 1993, p.60), com complemento infinitivo introduzido pela preposição para (Dá para sentir uma diferença, por exemplo).

Note-se, nos usos facultativos e deônticos orientados para o evento, um aumento de abstratização, de subjetividade, em comparação aos facultativos orientados para o participante. $\mathrm{O}$ verbo deixa de se referir a um estado físico de um participante (vocação, tendência), e passa a referir a uma atividade, a um evento, que é avaliado em termos de possibilidade, de permissividade de sua realização.

O que se observa, portanto, é que, entre os orientados para o participante e os orientados para o evento, há uma mudança na camada de atuação (Propriedades Configuracionais e Estados-de-Coisas), acompanhada de diferenças em padrões estruturais e aumento de abstratização.

O valor facultativo orientado para o evento pode ser localizado, ainda, em outro padrão estrutural:

Padrão III - [Np + DAR PARA +Vp FoRMA NÃo FINITA $]$

Nesses casos, um $\mathrm{Np}$ é localizado em posição inicial e pode ser analisado como sujeito morfossintático da construção. A ocorrência em (8a) é um exemplo:

(8a) Estado - Mesmo com toda a popularidade, o sr. não ganhou dinheiro? Otelo - Olha, eu trabalhava na Urca e ganhava 200 mil réis por dia. A Linda Batista ganhava 500 mil. Isso não me incomodava porque os 200 mil réis davam para eu fazer o que quisesse. Era muito dinheiro.

(...) porque dava para eu fazer o que eu quisesse com os 200 mil réis.

Nessa ocorrência, dar expressa a modalidade facultativa orientada para o evento: existem condições circunstanciais (a posse dos 200 mil réis) que habilitam a ocorrência do evento (fazer o que eu quiser). Em (8a), os 200 mil réis é sujeito morfossintático da construção, mas, em termos semânticos, é adjunto adverbial, como mostra a paráfrase $(8 b)$.

A motivação do posicionamento do sintagma, em (8a), está no conflito entre estatuto dado, ativo, de um referente e sua localização em um domínio que não contribui para a coesão discursiva e continuidade referencial. Observe-se, em (8a), que o assunto, nesse momento da entrevista, é salário, e Otelo, o entrevistado, argumenta que, embora seu ordenado de 200 mil réis fosse menor que o de outra pessoa (Linda Batista), isso não o incomodava, porque esse valor permitia a ele fazer o que quisesse. Nesse momento da conversa, o elemento discursivamente relevante é, então, 200 mil réis. Por isso, este elemento é retomado pelo entrevistado e colocado em posição de destaque, no início da oração, assumindo a função pragmática de Tópico.

Há ajustes morfossintáticos. Na ocorrência (8a), há a perda da preposição com do adjunto adverbial, com os 200 mil réis. Pode-se verificar, ainda, concordância do verbo (davam) com o sujeito (200 mil réis).

Os casos de topicalização (PONTES, 1987) envolvem alterações na estrutura sintática motivadas por fatores pragmáticos. Um $\mathrm{Np}$ é localizado no início do

\footnotetext{
${ }^{8}$ Vp é verbal phrase, sintagma verbal.
} 
enunciado, uma posição de destaque na interação, porque é um elemento relevante, saliente no discurso.

$\mathrm{Na}$ GDF, a função Tópico é atribuída a um Subato do $\mathrm{NI}^{9}$ que tem função de sinalizar, no Ato Discursivo, como o Conteúdo Comunicado se relaciona ao registro construído gradualmente no Componente Contextual, fornecendo um tipo específico de orientação para o estoque de informação nova a ser apresentada.

Observe-se que a posição inicial dos enunciados é tradicionalmente relacionada à função sintática de sujeito. De acordo com Garcia Velasco (2013), é sabido que a posição de sujeito comumente é associada à codificação de informação dada e, por isso, quando há a intenção de destacar algum item, a posição que o item assume é a de sujeito, pois a codificação de um elemento como sujeito é uma estratégia para sinalizar seu estatuto ativo, dado, na interação verbal.

$\mathrm{Na}$ língua portuguesa, Pezatti (2015) indica que a atribuição da função Tópico é marcada pela colocação do Subato Tópico no início da construção, sempre em posições do domínio de PI (posição inicial) na codificação morfossintática, e "o candidato mais natural à função Tópico é, sem dúvida, o constituinte configuracional que morfossintaticamente desempenha a função de Sujeito" (PEZATTI, 2015, p.8).

Note-se que, nas ocorrências orientadas para o evento até aqui examinadas, o verbo dar estabelece uma relação morfossintática com o conteúdo modalizado (Dá para sentir uma diferença, por exemplo). Há, porém, ocorrências, como (9), em que o verbo dar estabelece dependência discursiva com o conteúdo modalizado.

\begin{abstract}
RAUL - Cinco horas da tarde. Então eu vi. Enorme, rapaz, um negócio muito bonito. Inclusive os jornais levaram a coisa pro lado sensacionalista: O cara viu o disco voador. "O profeta do apocalipse" Eu dei muita risada com isso. Mas não foi nada, foi um disco muito bonito. $O$ PASQUIM - Dá pra descrever o disco? RAUL - Dá, sim. Foi... era meio assim... prateado. Mas não dava pra ver nitidamente o prateado porque tinha uma aura alaranjada, bem forte, em volta.
\end{abstract}

Em (9), o uso da forma dá é motivado pelo uso anterior do interlocutor que pergunta sobre a possibilidade de se descrever o disco. A resposta com dá confirma a possibilidade.

Nesses casos, a forma impessoal dá é uma peça avulsa, rotinizada, com escopo sobre porções do discurso. O funcionamento da construção é relacionado ao fluxo conversacional, e o que merece ser destacado é o nível de atuação da construção nesses casos: há um aumento de escopo, em que a construção modal com dar passa a atuar como elemento do NI.

Propõe-se o seguinte padrão estrutural para esses usos, sempre facultativos orientados para o evento:

\footnotetext{
9 Para melhor compreensão de como se prevê, na GDF, a atribuição de função pragmática, considere-se que o Movimento, camada mais alta do NI, consiste em um ou mais Atos Discursivos, que, por sua vez, organiza-se em um esquema ilocucionário que abarca os participantes da interação e o Conteúdo Comunicado, composto por Subatos, entendidos como formas comunicativas de ação do falante, que podem ser de Atribuição (uma tentativa do Falante de evocar uma Propriedade (f) que se aplica a uma entidade), ou de Referência (uma tentativa do falante de evocar uma entidade, que será de um tipo particular de categoria semântica como, por exemplo, Indivíduo (x), Locação (l), Tempo (t), Razão (r). Quantidade (q)), e a esses Subatos podem ser atribuídas funções pragmáticas, como a de Tópico.
} 
Padrão IV - [DAR] FORMA IMPESSOAL

Dar, no padrão IV, fórmula avulsa do discurso, pode modalizar, ainda, um conteúdo do enunciado já enunciado por outro participante, como (10), ou um conteúdo enunciado pelo próprio locutor, como (11).

(10) Fanboy: Recentemente os quadrinhos tiveram a perda de um de seus maiores ídolos, Will Eisner, você poderia fazer alguns comentários acerca disso? Campos: Não dá.

(11) Você só começou a escrever com o rap? Não houve nada antes? Eu tentei fazer uns sambas, mas não deu... Samba é diferente. Eu aprendi a ser um cara ligeiro foi no rap.

A ocorrência (10) pode ser compreendida como não dá para fazer alguns comentários acerca disso, e (11), como Não deu para fazer uns sambas. Tais paráfrases indicam que o conteúdo escopado é enunciado anteriormente.

Como uma fórmula avulsa, exemplificada em (9)-(11), dar não estabelece relação modal canônica, no nível das proposições, mas atua no nível dos atos de fala, das relações interpessoais, é um elemento do NI.

Considerados os valores modais expressos por dar e os padrões estruturais nos quais ocorrem, resta apresentar indícios de rotinização que a pesquisa revelou, sendo um deles já enunciado: a predominância do valor facultativo orientado para o evento $(97 \%$ das ocorrências, 160/165), como em (4), entre outros exemplos apresentados.

A verificação dos contextos negativos, das formas flexionais do verbo e dos padrões estruturais revelou que há predominância de formas negativas $(64 \%$ das ocorrências, 106/165), no presente do indicativo (75\% das ocorrências, 123/165), na terceira pessoa do singular (99\% das ocorrências 164/165) e no padrão II, [DAR PARA + Vp FORMA NÃo FINITA] ESTRUTURA IMPESSOAL (83\% das ocorrências, 137/165). Tais resultados apontam para a rotinização da construção não dá para, como em (5), já apresentado.

\section{Padrões de usos modais de dar e hipóteses de desenvolvimento}

As análises revelam expansão dos escopos nos usos modais de dar em direção a camadas e níveis mais altos do modelo da GDF, aumento de gramaticalidade e de abstratização.

Os usos modais de dar examinados alocam-se nas camadas das Propriedades Configuracionais (f), dos Estados-de-Coisas (e), do NR, e se constituem como elementos do NI, revelando a trajetória (f) $>(e)>N I$, que é compatível com propostas de percursos gramaticais de mudança semântica e formal no próprio modelo da GDF (HENGEVELD, no prelo) e, ainda com outros estudos sobre o desenvolvimento no campo modal (BYBEE et al., 1994; TRAUGOTT; DASHER, 2002).

Na camada f, dar realiza-se como um verbo pleno, expressão de habilidade de um sujeito participante em termos de vocação, tendência, configurando-se a modalidade facultativa para o participante (Eu não dou para essas exibições).

Na camada $e$, dar atua como um quase-auxiliar (HEINE, 1993) introduzindo um verbo infinitivo por meio da preposição para. A interpretação modal, nesse caso, é facultativa orientada para o evento, em que se descreve a possibilidade de ocorrência de um evento em termos das condições circunstanciais que habilitam sua realização (Nos 
grandes veículos já dá para sentir uma diferença.), ou deôntica orientada para o evento, em que se descreve um estado de coisas como permitido em um sistema de convenções morais ou legais, regras de conduta (Não dá pra fazer um personagem que não retrate pelo menos um pouco do que o autor é.).

Como fórmula avulsa, dá tem seu funcionamento ligado ao fluxo conversacional, âmbito de incidência captável na interação, implicado na situação comunicativa, configurando-se como um elemento do NI.

A identificação de padrões estruturais, em associação com a expansão dos escopos capturada por meio do modelo da GDF, sugere deslizamento da construção, da gramática ao discurso, com aumento de abstratização e perda de propriedades lexicais, compatíveis com um processo de gramaticalização. Tais encaminhamentos podem ser ilustrados pela seguinte figura:

\begin{tabular}{|c|c|c|c|c|}
\hline $\begin{array}{c}\text { Verbo pleno } \\
{[\mathrm{Np}+\text { DAR PARA + }} \\
\text { Np }]\end{array}$ & $>$ & $\begin{array}{c}\text { Verbo quase-auxiliar } \\
\text { [DAR FORMA IMPESSOAL + PARA +Vp FORMA NÃO } \\
\text { FINITA }] \\
{[\mathrm{Np}+\text { DAR PARA + Vp FORMA NÃO FINITA }]}\end{array}$ & $>$ & $\begin{array}{c}\text { Fórmula avulsa } \\
\text { [DAR FORMA } \\
\text { IMPESSOAL] }\end{array}$ \\
\hline $\begin{array}{l}\text { Escopo dentro da } \\
\text { proposição } \\
\text { (f) }\end{array}$ & $>$ & $\begin{array}{c}\text { Escopo sobre a proposição } \\
\text { EsITA }\end{array}$ & $>$ & $\begin{array}{c}\text { Escopo sobre o } \\
\text { discurso } \\
\text { NI }\end{array}$ \\
\hline
\end{tabular}

Figura 4 - Trajetos de desenvolvimento de construções modais com dar

O esquema ilustra as extensões verificadas na análise dos usos modais de dar, a partir das quais é possível inferir um processo de mudança, que parte de formas plenas, se desenvolvem formas quase-auxiliares do verbo e daí construções avulsas do discurso. Essa hipótese de desenvolvimento do verbo dar no campo modal é baseada em generalizações sincrônicas, e requer comprovação diacrônica.

\section{Considerações finais}

O objetivo do artigo foi examinar padrões de comportamento linguístico do verbo dar em usos modais, identificando-se deslizamentos funcionais. Para tanto, utilizou-se a GDF como aparato teórico-metodológico, e analisaram-se entrevistas do português contemporâneo retiradas do Corpus do Português.

Neste estudo, dar em usos modais é localizado com os valores facultativo orientado para o evento e deôntico orientado para o evento. Embora não identificado nos textos selecionados para exame, argumentou-se que dar pode assumir, também, o valor facultativo orientado para o participante.

Propôs, então, quatro padrões estruturais para os usos modais de dar:

- Padrão I - [Np + DAR PARA + Np]

Eu não dou para essas exibições

- Padrão II - [DAR PARA + Vp FORMA NÃO FINIT A] ESTRUTURA IMPESSOAL

Dá para sentir a diferença

- Padrão III - [Np + DAR PARA + Vp FORMA NÃO FINIT A]

Os 200 réis davam para eu fazer o que quisesse 
- Padrão IV - [DAR] FORMA IMPESSOAL

Entrevistador - Dá para descrever o disco?

Entrevistado - Dá

O modelo da GDF permitiu verificar nos usos novos e cristalizados de dar uma sequência na expansão dos escopos, de participante, que se localiza na camada das Propriedades Configuracionais, do NR (padrão I), para uma camada mais alta na hierarquia do modelo adotado, a do Estado-de-Coisas (padrão II e II) e daí para o NI (padrão IV).

A pesquisa revelou, ainda, que o verbo dar, em usos modais, caracteriza-se por ocorrer frequentemente na expressão fixa e rotineira não dá para, uma forma negativa e impessoal no presente do indicativo, com o valor facultativo orientado para o evento.

\section{REFERÊNCIAS}

AUWERA, J. V.; PLUNGIAN, V. Modality's semantic map. Linguistic Typology 2, 1998, p. 79-124.

BYBEE, J. L.; PERKINS, R.D.; PAGLIUCA, W. The evolution of Grammar. Tense, Aspect and Modality in the Language of the world. Chicago: University of Chicago Press, 1994. 398 p.

CASSEB-GALVÃO, V.C. Gramática discursivo-funcional e teoria da gramaticalização: revisitando os usos de [diski] no português brasileiro. Filologia linguística portuguesa, n. 13(2), p. 305-335, 2011.

COELHO, S. M.; SILVA, S. E. P. O continuum de gramaticalização do verbo dar: de predicador a auxiliar. Scripta, Belo Horizonte, v. 18, n.34, p. 23-40, 2. Sem., 2014.

GARCIA VELASCO, D. G. Raising in functional discourse grammar. In: MACKENZIE, J. L.; OLBERTZ, H. (eds.). Casebook in Functional Discourse Grammar. Amsterdam/Philadelphia: John Benjamins Publishing, 2013. p. 249-275.

HEINE, B. Auxiliares - Cognitive forces and grammaticalization. New York / Oxford: Oxford University Press, 1993. 162 p.

HEINE, B.; CLAUDI, U.; HÜNNEMEYER, F. Grammaticalization: a Conceptual Framework. Chicago: The University of Chicago, 1991. 318 p.

HENGEVELD, K. A hierarchical approach to grammaticalization. In: HENGEVELD, K.; NARROG, H.; OLBERTZ, H. (eds.). The Grammaticalization of Tense, Aspect, Modality and Evidentiality from a Functional Perspective. Berlin: de Gruyter Mouton. (no prelo). $22 \mathrm{p}$.

Illocution, Mood and Modality. In: BOOIJ, G., LEHMANN, C., MUGDAN, J. (eds.). Morphology. A handbook on Inflection and Word Formation, v. 2. Berlin: Mouton de Gruyter, 2004. p. 1190-1201.

. The grammaticalization of tense and aspect. In: NARROG, H.; HEINE, B. (eds.). The handbook of grammaticalization. New York: Oxford University Press, 2011. p. 577-591. 
HENGEVELD, K.; HATTNHER, M. M. D. The grammaticalization of modal verbs in Brazilian Portuguese: A synchronic Approach. Journal of Portuguese Linguistics, 15, 1, p.1-14, 2016.

HENGEVELD, K.; MACKENZIE, J. L. Functional Discourse grammar: a typologically-based theory of language structure. Oxford: University Press, 2008. 503 p.

HOPPER, P. J.; TRAUGOTT, E. C. Grammaticalization. Cambridge: Cambridge University Press, 2003. 277 p.

KEIZER, E. The lexical-grammatical dichotomy in Functional Discourse Grammar. Alfa, São Paulo, 51 (2), p. 35-56, 2007.

OLBERTZ, H. The grammaticalization of the Spanish connector pues - a proposal for an FDG account. International Conference on Functional Discourse Grammar. Lisboa, 2010. (não publicado)

PALMER, F. R. Mood and Modality. Cambridge: Cambridge University Press, 1986. $237 \mathrm{p}$.

PEZATTI, E. G. Um novo olhar para uma velha questão: ordenação de constituintes e a expressão de tópico, foco e contraste em português. A gramática da oração: diferentes olhares. 1. ed. Natal: EDUFRN, 2015. p. 69-100.

PONTES, E. S. L. O tópico no português do Brasil. Campinas: Pontes, 1987. 169 p.

SALOMÃO, M. M. M. Construções modais com dar no português do Brasil: metáfora, uso e gramática. Revista de estudos da linguagem. Belo Horizonte, v. 16, n. 1, p. 83115, jan./jun. 2008.

SOUZA, E. R. F. Gramaticalização dos itens linguísticos assim, já e aí no português brasileiro: um estudo sob a perspectiva da gramática discursivo-funcional. 2009. $273 \mathrm{f}$. Tese (Doutorado em Linguística) - Instituto de Estudos da Linguagem, Universidade Estadual de Campinas, Campinas.

TRAUGOTT, E. C.; DASHER, R. B. Regularity in semantic change. Cambridge: Cambridge University Press, 2002. 341 p.

TRAUGOTT, E. C.; HEINE, B. (orgs.). Approaches to Grammaticalization. v.1 Amsterdam: John Benjamins, 1991. 360 p.

VELlOSO, M. A emergência da gramática: estudo da idiomatização da Construção modal com "dar" no Português do Brasil. 2007. 95 p. Dissertação (Mestrado em Letras) Universidade Federal de Juiz de Fora, Juiz de Fora.

Recebido em: 05/10/2015

Aprovado em: 25/06/2016 